\title{
Effect of Land Pricing on Residential Density Pattern in Akure, Nigeria.
}

\author{
Fasakin J. 0. \\ 2016 TetFUND Research Group \\ Department of Urban and Regional Planning, \\ Federal University of Technology Akure, Nigeria \\ Basorun J. 0. \\ 2016 TetFUND Research Group \\ Department of Urban and Regional Planning, \\ Federal University of Technology Akure, Nigeria \\ Bello M. 0. \\ 2016 TetFUND Research Group \\ Department of Urban and Regional Planning, \\ Federal University of Technology Akure, Nigeria \\ Enisan 0. F. \\ 2016 TetFUND Research Group \\ Department of Estate Management, \\ Federal University of Technology Akure, Nigeria \\ Ojo B. \\ 2016 TetFUND Research Group \\ Department of Estate Management, \\ Federal University of Technology Akure, Nigeria

\section{Popoola 0. 0.} \\ 2016 TetFUND Research Group \\ Department of Urban and Regional Planning, \\ Federal University of Technology Akure, Nigeria
}

\begin{abstract}
Land pricing has produced a new order of residential density arrangement in Nigeria urban centres. There is a noticeable variation in land prices with the levels of residential density distribution in Akure, Nigeria. The research looked at the emergent residential density pattern in Akure, as a result of the pricing profile of land especially at the periphery of the city where three residential estates were randomly selected. With the use of GIS and IKONOS Imagery, the total number of buildings in the three estates was 5,104 [0ke-Ogba - 2,723; Obele - 2117 and Alagbaka - 264] out of which 10 percent, representing $\mathbf{5 1 0}$ were sampled. The Pearson Moment Correlation test revealed a significant correlation between Price and year of land purchase and the development, area of land, income of owners and household size. Policy measures were set forth for the development of mechanism for density mix that will fill the vacuum created due to rising land price in the city.
\end{abstract}

Keywords: land, price, residential, urban centre, Akure. 


\section{INTRODUCTION}

Residential housing sector plays a critical role in the development of an economy as it is one of the most basic needs of man [Mehmet, 2009]. In Nigeria, government owns the responsibility of providing affordable accommodation for its citizens irrespective of their location. Mabogunje (2002) observed that government had undertake some significant steps in meeting the demand for housing - the efforts which up till now have very limited impact on the housing needs especially for the low and middle income groups. Currently, many cannot afford a decent home because of lack of finance and escalating cost of land and building materials. In effect, majority of Nigeria's population now lives in slums and substandard accommodation in urban and semi-urban areas.

The situation is peculiar to Akure, where population grows at exponential rate and rapid urbanization is becoming a norm. Here, the discrepancy in housing need and supply is high as "most residents live in rented and sub-standard accommodation" [Lawanson, 2007]. Home ownership is one of the first priorities for most households and it represents the largest single investment. This becomes very significant when it is realized that per capital and real income in Nigeria have been on the decline. The prices of housing stock and the population groups served as well as the cost and problems of providing public services are all determined by the workings of the development process. The understanding of this process requires an examination of the relationships between land prices, the location and type of density in the city.

An explanation of land price requires more than expectations of future growths such as increase population, provision and development of infrastructure, land expansion among others (Shiller, 2007). Landowners vary widely with respect to their situation, knowledge and attitude, which affect both future expectations, real and perceived holding costs (Ilechukwu, 2010). Given the conventional assumptions, landowners should face a common future and should reach the same decisions with respect to development. Now that land prices vary directly with the level of expectation concerning future residential demand, higher price for land prompts developers to use less land in the construction of housing, substituting other inputs for land. In effect, there are variations in landowner expectations within each of the cities. As opined by Ebie (2003), when the landowners compare their initial expectations regarding returns from current development with the anticipated returns from future development, the patterns of residential densities vary between cities.

Density of residential development on land that is developed (and not withheld) may vary directly with land prices concerning future residential demand. Higher future demand in the city is more appealing, thus, causing more of these owners to withhold their land in favor of future development (Omirin, 1998). Ironically, a fast growing city like Akure, with more sprawls now faces housing challenges. The traditional assumption of employment being concentrated at the city center has become less tenable with the decentralization of commercial and industrial activities in the urban areas. The fact that it witnesses an unprecedented population growth in the last decade with no corresponding development on infrastructure and housing has led to the development of housing sprawl in some parts of the city (Aribigbola, 2008). This calls for a pragmatic planning approach in its development. In this research, land pricing in residential estates of Akure was carried out with the aim of providing a reliable framework for residential density development in the city.

\section{LITERATURE SEARCH}

The rate of urbanization in Nigeria has witnessed tremendous increase in the last two decades. Census in the early fifties showed that, there were about 56 cities in the country and about 
$10.6 \%$ of the total population lived in these cities. This rose dramatically to $19.1 \%$ in 1963 and $24.5 \%$ in 1985 . The national population was estimated to be about 150 million with the urban population constituting about 30\% (Ajanlekoko, 2011). The rapid growth rate of urban population in Nigeria since the early seventies was mainly due to immigration induced by the concentration of the gains from the oil sector in the urban areas (Oyesiku, 2009). Given the expected increase in urban population, the magnitude of housing problem in the country was enormous. In most of Nigerian urban centres, the problem of housing is not only restricted to quantity but to the poor quality of available housing units (Omole, 2001).

Unfortunately, the private sector is saddled with numerous problems which always make supply fall far short of demand and lower production quality (Nubi, 2008). The problem of qualitative housing has been a concern for both the government and individuals. Both public and private sector developers make effort through various activities to bridge the gap between housing supply and demand, but the cost of building materials, deficiency of housing finance arrangement, stringent loan conditions from mortgage banks, government policies amongst other problems have affected housing provision or delivery significantly in Nigeria (Raji, 2008). Rising land prices and charges also appear exorbitant in the city; much above the official income capacity of average Nigerian citizen. This is because when expectations about future development potential are high, more land will be withheld from development, land price and values will be higher, and the densities in developed areas will be higher.

Residential Density is used as a measurement of the spatial concentration of populations. There are a number of definitions of residential density within urban areas. Definitions used in the analysis of settlement densities in Sydney's urban areas (Cardew, 1996) range from site density to metropolitan density. National State of the Environment report, defines the concept as the area of land within urban centres designated for 'residential land use' divided by total population resident in those centres (Newton et al., 1998). The human settlement environment is strongly influenced by settlement density. Both high density and the high per capita land consumption rates associated with low density development can have negative environmental consequences. Higher settlement densities can concentrate pollutants within the urban environment, but can reduce the impact of residential development on surrounding ecosystems and reduce energy and resource use.

Literature has shown that mixed density is one of the built environment features that contribute to increased active transport, along with mixed land use planning and increased connectivity (Gebel et al, 2005). At the regional and city wide scale, increasing housing density can improve the proximity between homes and destinations. This is a major factor influencing active transport. Concentrating residential density in compact and well designed urban areas allows the city to provide infrastructure and services more efficiently and cost-effectively. As new settlements emerge and existing settlements change, promoting higher density living is one of the main ways we can manage population growth. A diversity of housing choices is a key characteristic of 'complete settlement'

Governments often set targets for residential density to assist with targets for growth and to achieve sustainable outcomes for a city, region or suburb. Housing density is calculated by either the number of dwellings per hectare or by the number of people per hectare. Providing residential density through a mixture of low, medium and high densities is a way of achieving these targets. As part of the Land Use Plan, definitions of existing land uses are provided to indicate the current status of properties within the planning area. The plan also applies the same definitions to express future land uses for every parcel area to clearly state future expectations for development. The utilization of common definition for both existing and 
future conditions permits comparison between today's conditions and expected conditions at build-out (Edwards, 2012). Land price is one of the factors inhibiting a good density mix in Nigerian residential areas which attracts little or no attention in urban development. This is an area that has posed greater challenges in terms of housing problems in the past two decades.

\section{The Study Area}

\section{MATERIALS AND METHOD}

The research was limited to the urban periphery of Akure, where residential neighbourhoods formed the focus of study. In the area, three (3) residential estates were selected randomly. These are M. A. Adesida Estate in Alagbaka, Obele Estate along Ijare Road and Oke-Ogba Estate along Agagu Road. The study focused purposely on these areas to determine the effects of land price on the residential density pattern for necessary planning intervention.

Akure is a traditional Nigerian city and like other traditional Yoruba towns in the country, it existed long before the advent of British colonial rule in Nigeria. The city situates in the South Western part of Nigeria. It lies approximately on latitude $7^{0} 15^{\prime}$ North of the Equator and longitude $5^{0} 15^{\prime}$ East of the Greenwich Meridian (Macmillan, 2006). Akure is a medium- sized urban centre which became the provincial headquarters of Ondo province in 1939. It became both the capital city of Ondo State and Akure Local Government Council Headquarters in 1976. Consequently, there was heterogeneous massing of people and activities in the city. The city's morphology has changed over time to assume its present status with its attendant housing problems, as experienced in similar medium sized urban centres in Nigeria. Akure is located approximately 420 kilometres South West of Abuja, the Federal Capital of Nigeria and about 350 kilometres to Lagos the former capital of Nigeria. 


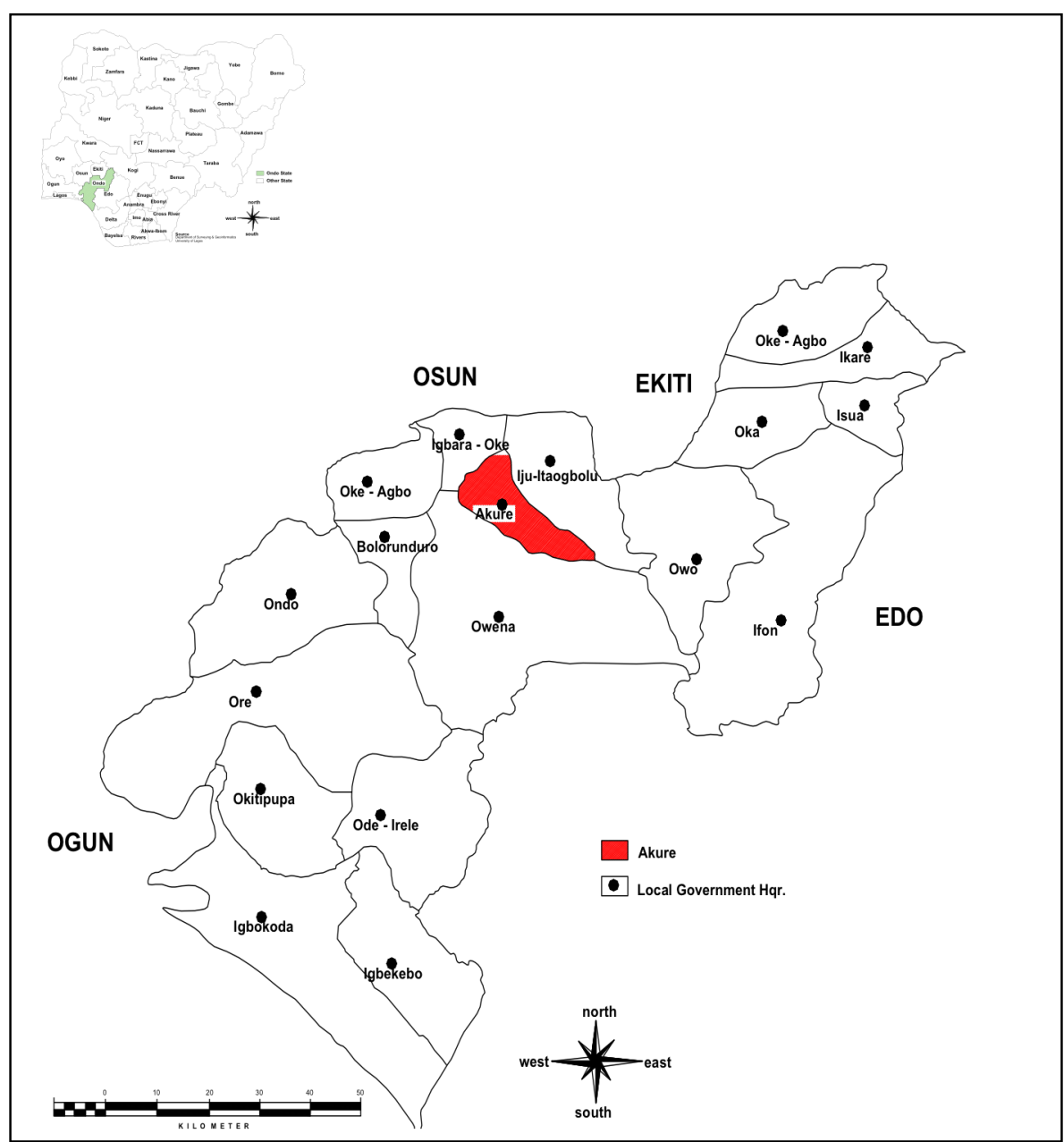

Fig. 1: Akure in Ondo State, Nigeria

Source: Department of Urban \& Regional Planning, Federal University of Technology, Akure, 2016

The population of the city grew from 38, 852 in 1952 to 71,106 in 1963. Its population was estimated to be 112,850 in 1980 and 157,947 in 1990 (Ondo State of Nigeria, 1990). The 1991 National Population Census put the population of Akure at 239,124 while its estimate for 1996 was 269,207 (NPC, 1997). The population figure of Akure as determined in the 2006 population census was 353,211 (NPC, 2006). This was projected to 2016 with an estimate of 483,047 people using the $3.18 \%$ annual growth rate officially supplied by the National Population Commission. The population of Akure was estimated to be over a million people (Aribigbola, 2008).

Empirical investigations and observations of urban dynamics in Akure indicate that at the moment, urban planning has very little influence over the process of land management in the city. The changes in land use patterns were as a result of series of ad-hoc solutions. For instance, Ondo state is one of the 13 beneficiary states in Nigeria under the World Bank Assisted Community Based Urban development project. Thus, two communities: Oke Aro, Eyinke and Irowo/Odopetu were identified in Akure to benefit from the project. Under the project, infrastructure and municipal services such as roads, water supply, and waste management scheme were upgraded and provided in the selected communities (Aribigbola, 2008).

\section{Data Collection Method}

The three residential neighbourhoods chosen constitute the sample frame for questionnaire administration for the study. This comprises of Oke Ogba, Obele and Adesida housing estates. 
In order to determine the sample size for the study, the maps of the three residential estates were produced showing the number of buildings. Grid method was employed to divide each map into equal squares. Total numbers of buildings in the selected residential estates were counted using GIS and IKONOS Imagery.

Oke Ogba had 2,723 buildings, Obele 2,117 buildings and Alagbaka 264 buildings of which 10\% of the total number of buildings on each of the maps was selected resulting to 272 buildings, 212 buildings and 26 buildings for Oke Ogba, Obele and Alagbaka housing estates respectively. The random number generator with the aid of Graph Pad Software was used to select grids. Graph Pad Software (Quick Calcs), which is scientific software was used to create a table of random number. Using the table of random numbers, for Oke Ogba, the numbers selected were $9,13,14$, and 15 (grids) for 97 buildings, 44 buildings, 60 buildings and 71 buildings respectively. For Obele estate, the numbers selected were 7, 17, 15, and 3 (grids) for 54 buildings, 82 buildings, 37 buildings and 39 buildings respectively. While at Alagbaka housing estate, the numbers selected were 2 and 7 (grids) for 20 buildings and 6 buildings respectively.

Simple random sampling technique with replacement was used to select buildings in the study area. Where the selected building on the map was discovered to be for commercial, religious or industrial purpose on ground, it was replaced with the residential building nearest to it. The choice of respondents was not restricted to the head of household alone, given that the study was not strictly on household heads. Structured questionnaire was employed to collect data from the study population. The data was collected with the support of field assistants who are students of the Federal University of Technology, Akure. The students were trained on how to administer questionnaire under the supervision of fieldwork coordinators. The questionnaires were administered between the hours of 4:30 - 7:00pm (evenings), when majority of the respondents were at home. Five field assistants were employed to administer the questionnaires. The questionnaire administration lasted for five weeks. Further relevant information for the study was collected from in-situ observations, photographs, informal interviews and discussions with the respondents. 


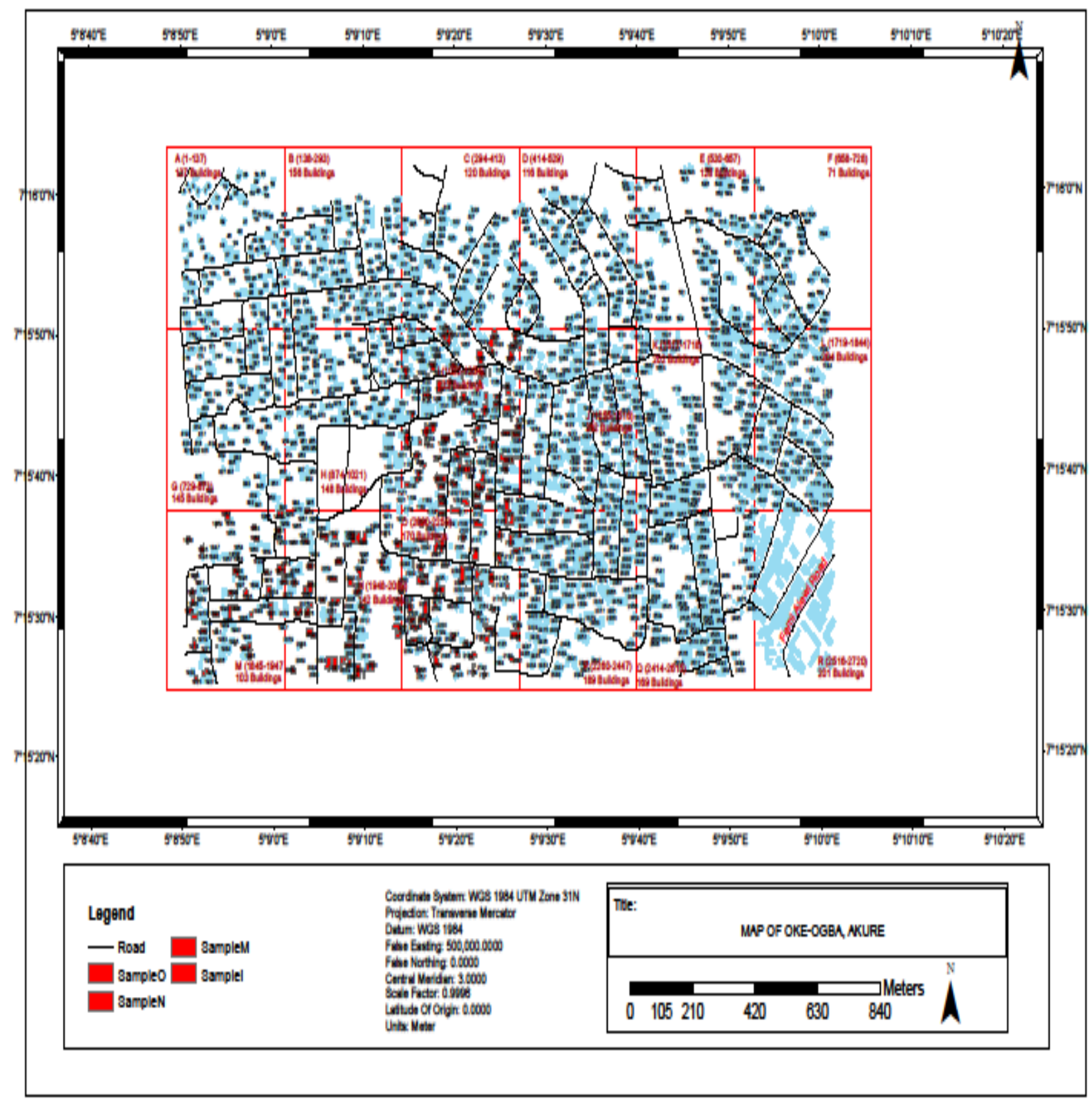

Figure 2: Selected Buildings in Oke Ogba Community, Akure, Ondo State.

Source: Author s' Fieldwork, 2016. 


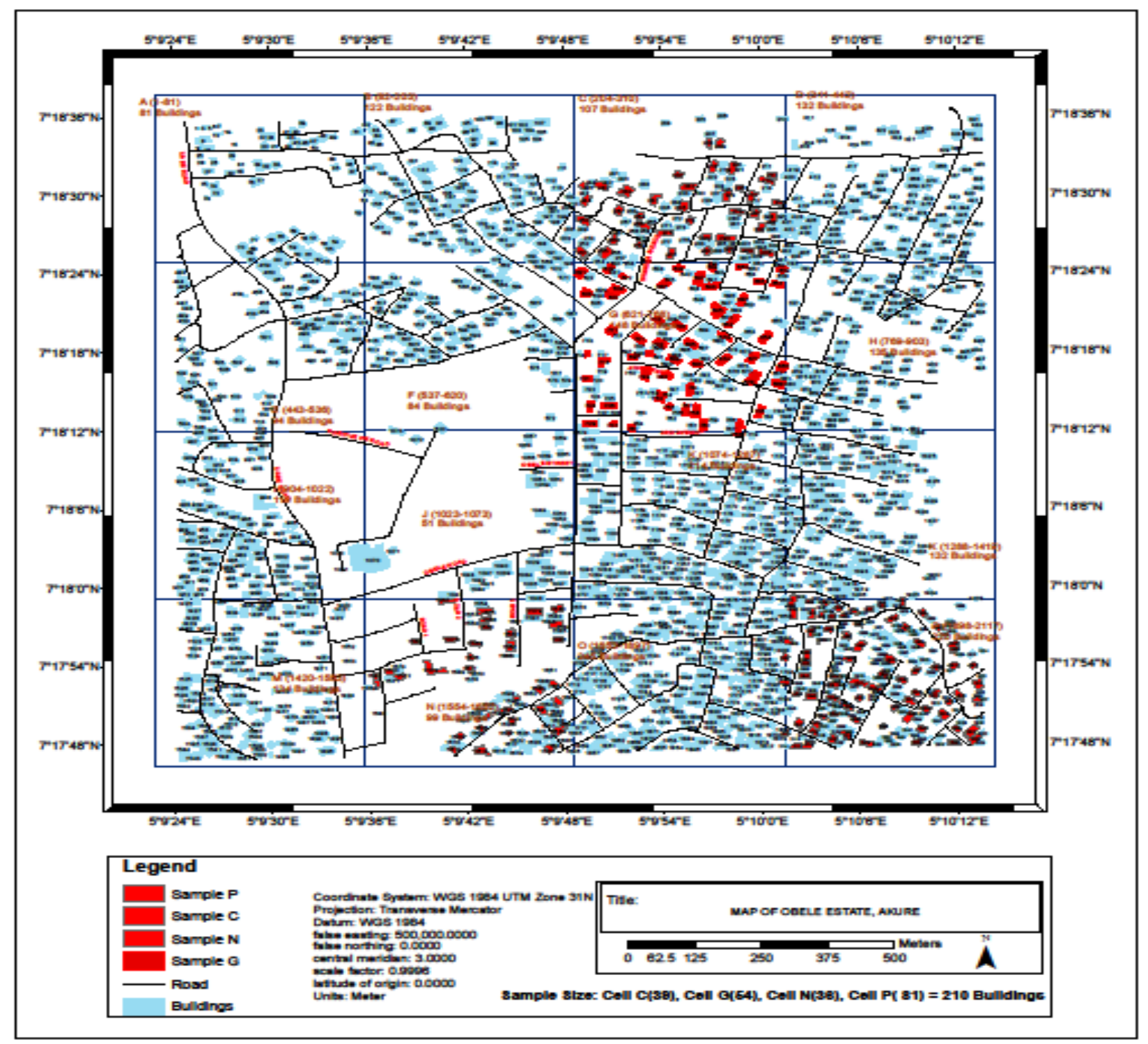

Figure 3: Selected Buildings in Obele Housing Estate, Akure, Ondo State. Source: Author s' Fieldwork, 2016. 


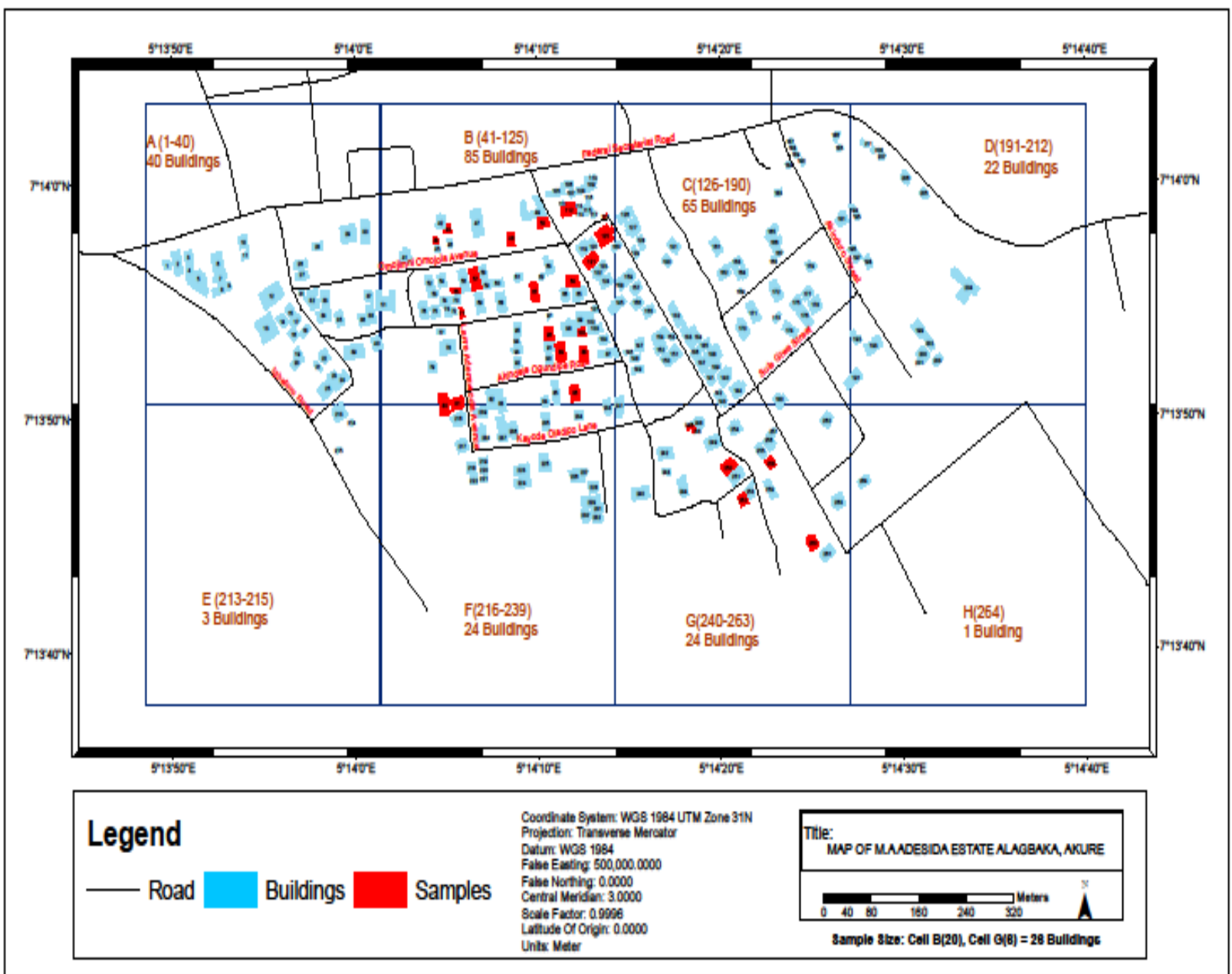

Figure 4: Selected Buildings in Alagbaka Housing Estate, Akure, Ondo State. Source: Author s' Fieldwork, 2016.

\section{RESEARCH FINDINGS}

\section{Relationship between Price and Housing Density Variables}

The main thrust of this research is to assess price in relation to the various housing densities noticeable. The housing densities include the high, medium and low. The study is to ascertain if the price of land has any relationship with other variables of housing densities. On this note, the price variable has been calibrated to depict the variations in densities. For example, price below $\$ 200,000$ (\$526.3) could signify a high-density plot; prices between $\$ 200,000$ and $\$ 500,000$ (\$526.3 and $\$ 1,315.8$ ) a medium-density plot; while above $\$ 500,000(\$ 1,315.8)$ could be a low-density plot. High density was dominant (53.3\%) in all the residential neighbourhoods in the study area. The medium housing density accounted for $37.5 \%$ while the low density had $7.2 \%$. The building coverage of the plot areas in the densities were $74.8 \%$, $22.8 \%$ and $2.4 \%$ respectively - a strong indication that Akure needs re-planning to create better residential density mix through zoning. The task is to examine the relationship between price and the variables of housing density mix leading to the development of a model pricing mechanism, which will also serve as a predictive framework useful for prospective landowners, house owners and the various parastatals in charge of land and housing development. 


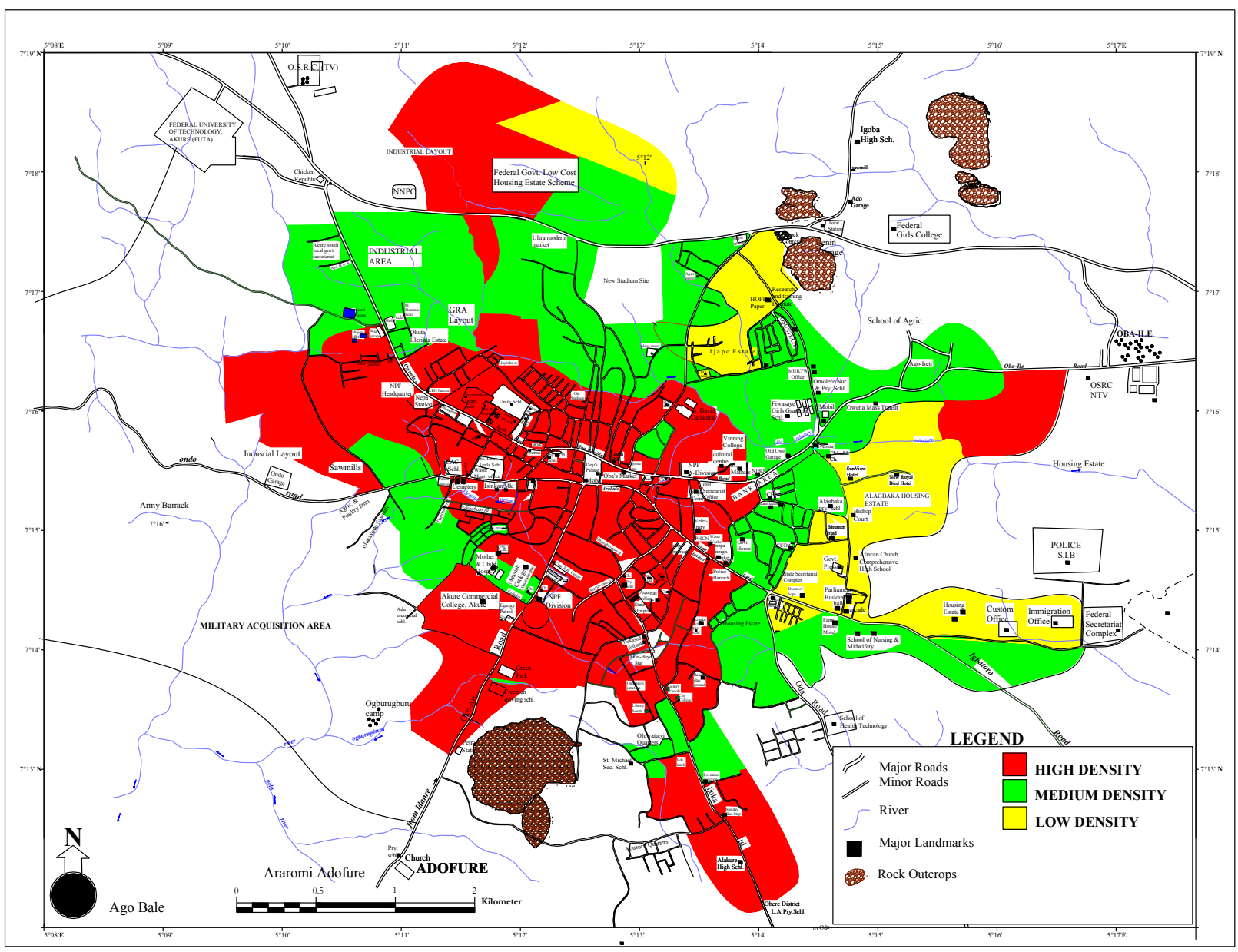

Figure 5: Housing Densities Pattern in Akure Source: Author s' Fieldwork, 2016.

\section{Correlation Matrix between Price and Housing Density Variables}

Table 1 presents the correlation matrix of price and housing density variables in the study area. There is a statistically significant relationships between the paired variables at $\mathrm{P}<0.01$ and $\mathrm{P}<0.05$ levels. The number of persons per building (PERSON-B) and number of families per plot (FAMILY-P) had strong positive significant relationship, with a correlation coefficient of 0.537 and $\mathrm{P}<0.01$. Physical density is a numerical measure of the concentration of individuals or physical structures within a given geographical unit. It is an objective, quantitative and neutral spatial indicator. However, in practice, physical density takes a real meaning only if it is related to a specified scale of reference. For instance, density expressed as ratio of population to land area can vary significantly with reference to different scales of geographical unit. Nevertheless, there is no standard measure of density; there are only measures that are more widely used than others. In town planning, measurement of physical density can be broadly divided into two categories: demographic density and building density. Demographic density is expressed as the number of people or household per given area, while building density is defined as the ratio of building structures to an area unit (Vicky, 2012).

Occupancy density refers to the ratio of the number of occupants to the floor area of an individual habitable unit. The habitable unit can be any kind of private or public space, such as a dwelling, office, theatre and so on. However, the reference area usually refers only to an enclosed area. Occupancy density is an important measure in building services design as it provides an indicator for estimating the services required. For instance, the electricity demand, space cooling and heating load, provision of fire safety facilities, and so forth are estimated based on the occupancy density. Occupancy rate, which is the inverse measure of occupancy 
density (that is, ratio of floor area of individual unit to number of occupants), is commonly used as an indicator of space available for individual occupants. Higher occupancy rate means larger habitable area for individual occupants. Regulation of minimum occupancy rate is often used in building design to safeguard the health and sanitary condition of habitable spaces (Vicky, 2012).

Table 1: Correlation Matrix between Price and Housing Density Variables

\begin{tabular}{|c|c|c|c|c|c|c|c|c|c|c|}
\hline & $\begin{array}{l}\text { 됨 } \\
\text { 좀 }\end{array}$ & 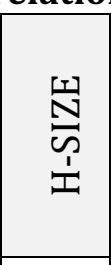 & 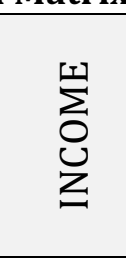 & 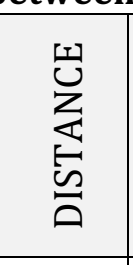 & 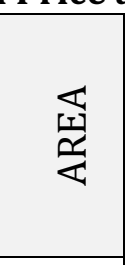 & 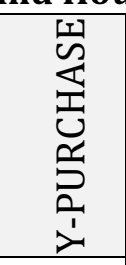 & $\underset{⿱ 亠 乂}{2}$ & $\begin{array}{l}n \\
z^{1} \\
0 \\
\mathscr{n} \\
\frac{1}{2}\end{array}$ & 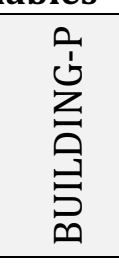 & 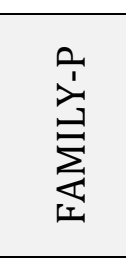 \\
\hline PRICE & 1.00 & $\begin{array}{c}- \\
.098^{*} \\
\end{array}$ & $.161^{* *}$ & -.065 & $-.098^{*}$ & $.309^{* *}$ & $.231^{* *}$ & .035 & .010 & .032 \\
\hline H-SIZE & & 1.00 & $-.097^{*}$ & -.059 & .080 & -.054 & -.045 & $.306^{* *}$ & .059 & -.034 \\
\hline INCOME & & & 1.000 & .032 & .079 & $.164^{* *}$ & .080 & .070 & -.001 & $.126^{* *}$ \\
\hline DISTANCE & & & & 1.000 & .011 & $.135^{* *}$ & .083 & -.015 & -.030 & -.030 \\
\hline AREA & & & & & 1.000 & .008 & -.016 & -.032 & -.046 & -.049 \\
\hline $\begin{array}{l}\text { Y- } \\
\text { PURCHASE }\end{array}$ & & & & & & 1.000 & $.558^{* *}$ & $.122^{* *}$ & $.111^{*}$ & $.173^{* *}$ \\
\hline Y-DEVT & & & & & & & 1.000 & $.108^{*}$ & .064 & $\begin{array}{c}8.168^{*} \\
*\end{array}$ \\
\hline PERSON-B & & & & & & & & 1.000 & $.171^{* *}$ & $.537^{* *}$ \\
\hline BUILDING-P & & & & & & & & & 1.000 & $.353^{* *}$ \\
\hline FAMILY-P & & & & & & & & & & 1.000 \\
\hline
\end{tabular}

** Correlation is significant at the 0.01 level (2-tailed).

* Correlation is significant at the 0.05 level (2-tailed).

KEY: PRICE = Price of plot; H-SIZE = Household size; INCOME = Income of respondents; DISTANCE = Distance to the city core; $A R E A=$ Land area; Y-PURCHASE = Year of purchase; YDEVT = Year of development; PERSON-B = Number of persons per building; BUILDING-P = Number of buildings per plot; and FAMILY-P = Number of families per plot.

The relationship between year of purchase (Y-PURCHASE) and year of development (Y-DEVT) proved to be strongly significant with coefficient of correlation of 0.558 and $P<0.01$. Similarly, the relationship between year of purchase of land (Y-PURCHASE) and price of plot (PRICE) is moderately positive and significant with $\mathrm{R}=0.309, \mathrm{P}<0.05$. The supply of land is not very responsive to its price, which means that it can be electronically prized without significantly misleading people. The ownership of land is also generally visible and easily established which makes it relatively convenient to identify the owner. The fact that land has identifiable and unchangeable geographic locations also makes them accessible. However, there are a number of reasons why the relationship between year of purchase and development of land in the study area is important. First, this finding is not unconnected with the volatility of land prices within a year which depends on the wide variation of the prices within certain geographical areas over the years. Second, in an economy characterized by inflation and whimsical determination of land prices, it is not implausible to see that the year of purchase may have a low relationship with the price of purchase. Ordinarily, the farther the years, the lower the prices of land for any geographical area.

However, household size (H-SIZE) and the number of persons per building (PERSON-B) analysis showed a positive significant relationship which is also moderate. With fewer persons 
in each household, there will be more living space available per person. No doubt, the average number of persons per room (used for living purposes), the general housing and living condition will improve. The relationship between year of development (Y-DEVT) and price of plot (PRICE) as well as income levels of residents (INCOME) and number of families per plot (FAMILY-P) are significantly weak (R 0.231 ) and very weak (R 0.184 ) respectively. All things being equal, plots bought early were expected to attract low prices as urban frontier expansion tends to shoot land prices at the periphery. However, higher prices of land in subsequent years after the purchase tend to encourage land speculation. Thus, land buyers in the recent past are expected to sell at higher prices than those buyers in more distant past. The rise could be so unsteady as to vitiate time of purchase for plots especially for those that are close to the core.

\section{POLICY RECOMMENDATION}

The study revealed the range of land prices and its resultant effect on residential density pattern in Akure, Nigeria. The relationship between land price and density pattern also shows that, if land prices are regulated by government, development pattern will be controlled. This will enhance balanced and liveable environment and also eliminate sprawl development that were noticeable during the survey in the residential Neigbourhoods. The correlation test has indicated that if proper land mechanism is put in place with requisite housing density mix, the land value in the area will be enhanced. For Akure to develop and eliminate filthy structures that characterize the areas; there is need for the Ondo State Government through the Land Bureau Office of the Ministry of Lands and Housing to coordinate land pricing that will designate areas of different residential densities through zoning. This can be done through eland pricing mechanism that will ensure prompt management of residential density development. The land pricing will ensure that land in a particular zone has relative uniform pricing. This will also give the assurance that Akure does not develop into slum as land reorganization will be accompanied through the e-land pricing mechanism. The model will limit the manner in which land are sold at will by the land owners in the area.

\section{ACKNOWLEDGEMENT}

The authors deeply acknowledge the sponsorship of the research by the Federal University of Technology, Akure through the TETFund Research Grant of the federal Government of Nigeria form which this article emerged.

\section{Reference}

Aribigbola, A. (2008). Urban Land Use Planning, Policies and Management in Sub Saharan Africa. Department of Geography and Planning Sciences, Adekunle Ajasin University, Akungba Akoko

Ajanlekoko, J. O. (2011): Construction Development Bank: A Panacea for Affordable Housing and Infrastructural Development in Nigeria. A paper Delivered at the $4^{\text {th }}$ Annual Lecture of the School of Environmental Technology, Federal University of Technology, Akure, Ondo State.

Cardew, R. (1996). Residential density in Sidney. Australian Planners, 33(2), 105-113

Ebie, F. (2003): Greater Prospect Ahead in the Mortgage Sector. House and Property Magazine, 1(2), 43-49.

Edwards F (2012). The regional spatial strategy for the South West 2006 - 2026. Information Note 11: Housing mix, type and density. Southwest Regional Board (http//www.southwest-ra.gov.uk).

Gebel, K. King, L., Bauman, A., Vita, P., Gill, T., Rigby, A. \& Capon, A. (2005). Creating healthy environments: A review of the links between the physical environment, physical activity and obesity. Sydney, NSW Health Department and NSW. Centre for overweight and obesity.

Ilechukwu, V., (2010): Land Values and Housing Densities in Nigerian Cities: The Case of Onitsha. Urban and Regional Planning Review, Department of Urban and Regional Planning, University of Lagos. 1 (3), 87-94

Lawanson, O. T. (2007): Poverty and Environmental Degradation in the Lagos Metropolis. Journal of Environmental Science. 11 (1), 36-65 
Mabogunje, A. (2002): Housing Delivery Problems in Nigeria. Punch Newspaper, Wednesday, May, 2002.

Macmillan (2006): Beyond Scarcity: Power, Poverty and the Global Water Crisis. Human Development Report. United Nations Development Programme (UNDP).

Mehmet Topçu (2009) Accessibility Effect on Urban Land Value. Scientific Research and Essay. 4 (11), 1286-1291, http: //www.academic journals. org/ SREISSN 1992-2248.

National Population Commission [Nigeria] (1997). National Housing and Demographic Survey. Abuja, Nigeria: National Population Commission.

Nubi, O. T. (2008). Affordable housing delivery in Nigeria. The South African Foundation International conference and exhibition. Cape Town, October, 1-18.

Omirin, M. M., (1998): Land Accessibility and Low Income House Building. Journal of Environmental Studies 1, University of Lagos: Book Policy, Lagos

Omole F.K (2001): Basic issues in Housing Development. Akure; Femobless Publishers

Oyesiku, K. (2009): City Liveability: Implications and Challenges. Paper presented at the 2009 Commonwealth Association of Planners, West Africa Workshop on Planning for Liveable Human Settlement: The West African Challenges, Lagos.

Raji, O. (2008). Public and private developers as agents in urban housing delivery in Sub-Saharan Africa:The Situation in Lagos State. Humanity of Social Sciences Journal, 3 (2), 143-150.

Shiller, R. J., (2007): Understanding Recent Trends in House Price and Home Ownership. Paper Presented at Federal Reserve Bank of Kansa City Conference at Jackson Hole, August 31

Vicky, C. (2012). Understanding density and high density.

ttps://arhitectura2tm.files.wordpress.com/2012/09/understanding-density-and-high-density.pdf 